\title{
Relationship between weakness and muscle wasting in rheumatoid arthritis
}

\author{
P S Helliwell, S Jackson
}

\begin{abstract}
Objective-To relate weakness of grip to loss of forearm muscle bulk, hand joint deformity, and hand joint tenderness in patients with rheumatoid arthritis (RA).

Methods-Using anthropometric data we have estimated the anatomical crosssectional area (CSA) of forearm muscles in 100 subjects with RA compared with 100 aged and sex-matched normal subjects. We also recorded hand joint tenderness using a modification of the Ritchie articular index, and a simple index of hand joint deformity.

Results-We found a significant reduction in anatomical CSA in RA (forearm CSA in normal subjects $29.7 \mathrm{~cm}^{2}$ and in RA 25.9 $\left.\mathrm{cm}^{2} ; \mathbf{p}=0 \cdot 002\right)$. In simple linear regression we found that $46 \cdot 3 \%$ of the variation in grip strength in normal subjects was explained by variation in muscle CSA; in RA this figure decreased to $33 \cdot 4 \%$. Adding terms for joint deformity and pain in a multiple regression model improved the amount of variation explained to $37.9 \%$. Conclusions-Although there is significant muscle wasting in RA, it is likely that reduction in strength is also attributable to joint deformity and pain leading to inhibition of grip directly and, indirectly, by arthrogenous muscle inhibition. Doubts remain about the quality of muscle in RA.
\end{abstract}

(Ann Rheum Dis 1994; 53: 726-728)

While pain and stiffness are the main symptoms of rheumatoid arthritis (RA), they are closely followed by weakness, particularly of grip strength. ${ }^{12}$ There are several possible reasons for this weakness. Patients often complain that their limbs seem to have lost bulk and it is known that systemic disease and disuse lead to a reduction in fibre diameter and hence in muscle bulk. ${ }^{3}$ However, direct involvement of muscle by an inflammatory process may contribute, ${ }^{5}$ and joint inflammation and deformity influence muscle function as a result of afferent impulses from joint mechanoreceptors and joint nocioceptors-so called arthrogenous reflex muscle inhibition. ${ }^{6}$ In some patients other factors may be important. For example, when deformity is severe the mechanical advantage of the muscle may be compromised. Finally, muscle function may be affected by inflammation and attrition of tendons and disruption of tendinous insertions.
The force a muscle can produce is independent of fibre type and is related to the physiological cross-sectional area (CSA) of the muscle. Physiological CSA is a function of muscle mass, muscle density, fascicle length and angle of pennation. Anatomical CSA underestimates physiological CSA by about $30 \%$, but for comparative purposes anatomical CSA correlates well with strength. ${ }^{4}{ }^{7}$ It is surprising, therefore, that although patients complain of loss of muscle bulk, previous measurements of forearm CSA in patients with RA have been unable to show a significant difference from that in normal subjects. ${ }^{8}$

The aim of this study was to obtain a precise measure of forearm anatomical CSA in a large group of subjects with RA, to obtain comparative data from a matched group of normal subjects, and to relate muscle CSA to grip and pinch strength. We also collected data on joint deformity and joint pain in the hand in order to relate these variables to the loss of strength found in RA.

\section{Methods}

Ethics committee approval for this study was obtained. Normal subjects were recruited from social centres catering for elderly people (Help the Aged), members and staff of the University of Leeds and from a crown green bowling club. Our aim was to recruit a control population of similar age, sex, height, and weight, but we did not directly match the controls with the cases. Patients with RA all had disease diagnosed according to the criteria of Arnett et al, ${ }^{9}$ and were mainly recruited from outpatient clinics.

Grip and pinch strength were measured with a digital pinch grip analyser (MIE Medical Research Ltd, Leeds). Pinch strength was measured between thumb pulp and the radial side of the index finger. The dominant hand was measured in all cases. Anthropometric data recorded were: height, weight, forearm length measured between the lateral epicondyle and the ulnar styloid process, mid-forearm circumference, skin and subcutaneous tissue thickness using a standard caliper ('John Bull' Harpendon Skinfold Caliper, British Indicators Ltd) measured on both dorsal and ventral surface at the mid-point of the forearm.

Forearm muscle CSA was calculated as follows:

$\operatorname{CSA}\left(\mathrm{cm}^{2}\right)=\pi\left(\frac{\mathrm{FOC}}{2 \pi}-\frac{\mathrm{ST}_{\mathrm{d}}+\mathrm{ST}_{\mathrm{v}}}{40}\right)^{2}-\mathrm{R}-\mathrm{U}$

where $\mathrm{FOC}=$ forearm circumference $(\mathrm{cm})$; $\mathrm{ST}_{\mathrm{d}}=$ dorsal skin thickness $(\mathrm{mm}) ; \mathrm{ST}_{\mathrm{v}}=$ ventral skin thickness $(\mathrm{mm}) ; \mathrm{R}=$ area of radius

The Rheumatology and
Rehabilitation
Research Unit, 36
Clarendon Road,
Leeds LS2 9NZ, United
Kingdom
P S Helliwell
S Jackson
Correspondence to:
Dr Helliwell.
Accepted for publication
7 July 1994




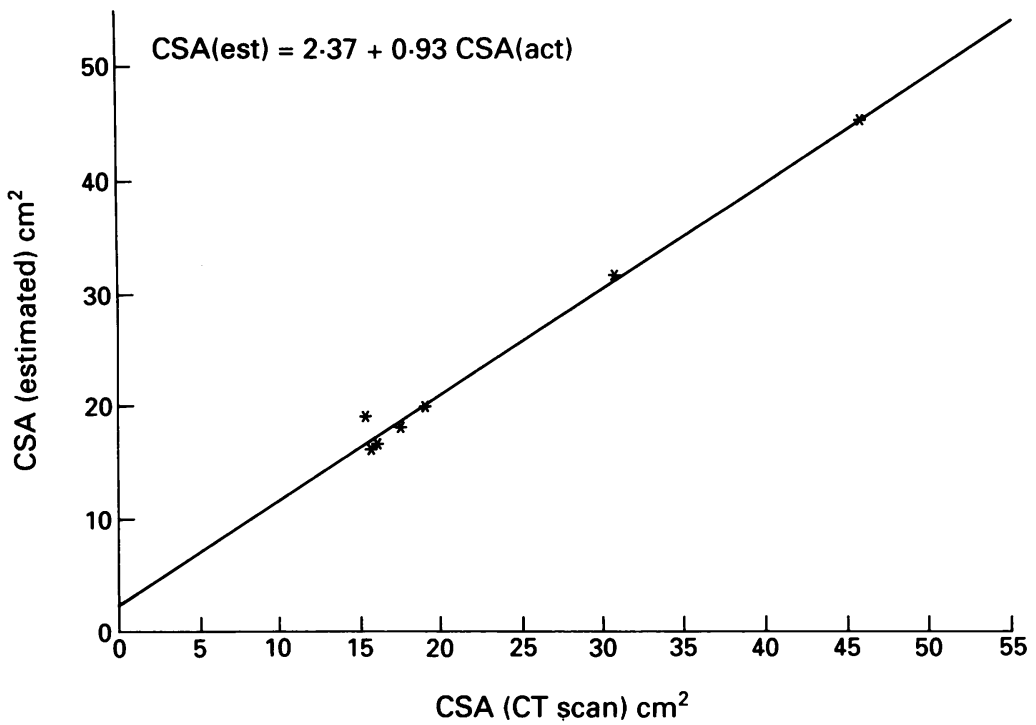

Figure 1 Relationship between estimated (est) (from anthropometric measurements) forearm muscle cross-sectional area (CSA-estimated) and actual (act) (from computed tomography) forearm muscle cross-sectional area (CSA-CT scan).

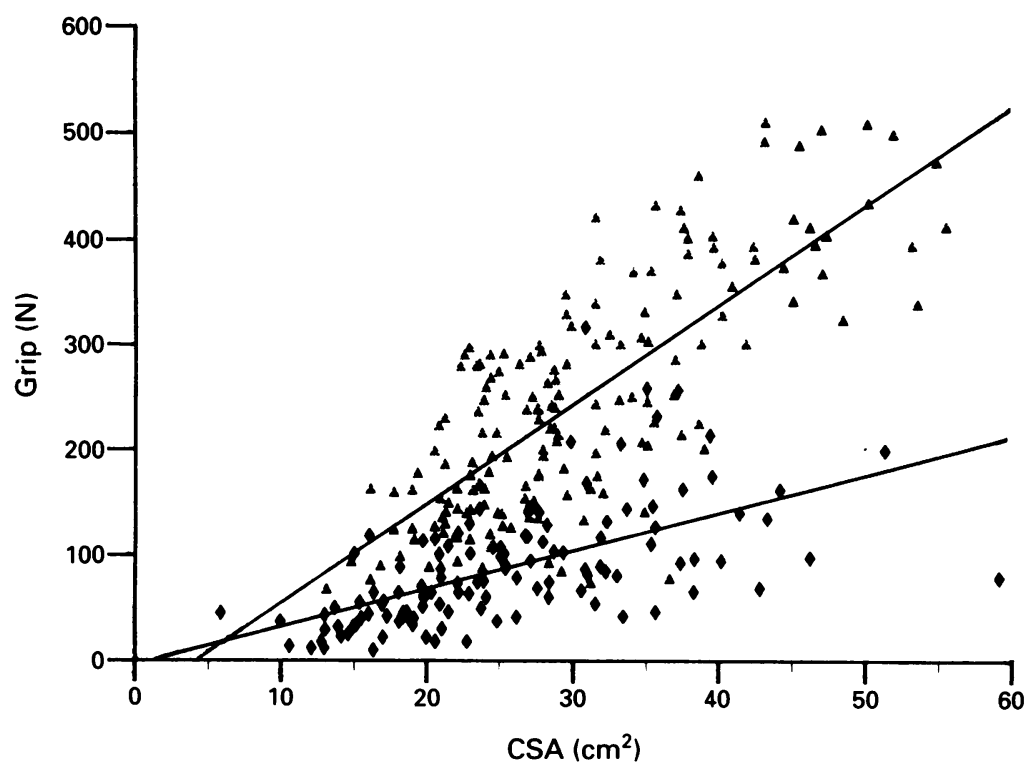

Figure 2 Relationship between anatomical muscle cross-sectional area (CSA) and maximum grip strength in normal subjects ( $\mathbf{\Delta})$ and patients with rheumatoid arthritis $(\bullet)$.

Table 1 Mean (SD) age, sex, height, weight, strength and muscle cross-sectional area (CSA) in study participants

\begin{tabular}{|c|c|c|c|}
\hline & $\begin{array}{l}\text { Normals } \\
(n=100)\end{array}$ & $\begin{array}{l}R A \\
(n=100)\end{array}$ & $\begin{array}{l}95 \% \text { CI } \\
\text { for difference } \\
\text { between groups }\end{array}$ \\
\hline $\begin{array}{l}\text { Sex }(M: F) \\
\text { Age }(\mathrm{yr}) \\
\text { Height }(\mathrm{m}) \\
\text { Weight }(\mathrm{kg}) \\
\text { Maximum grip (N) } \\
\text { Maximum pinch (N) } \\
\text { Forearm muscle CSA }\left(\mathrm{cm}^{2}\right)\end{array}$ & $\begin{array}{l}32: 68 \\
57 \cdot 2(20 \cdot 0) \\
1 \cdot 66(0 \cdot 09) \\
67 \cdot 5(12 \cdot 9) \\
223 \cdot 1(100 \cdot 5) \\
74 \cdot 7(22 \cdot 3) \\
29 \cdot 7(7 \cdot 5)\end{array}$ & $\begin{array}{l}31: 69 \\
58 \cdot 9(12 \cdot 9) \\
1 \cdot 64(0 \cdot 10) \\
66 \cdot 4(13 \cdot 9) \\
92 \cdot 6(58 \cdot 1) \\
40 \cdot 8(20 \cdot 0) \\
25 \cdot 9(9 \cdot 5)\end{array}$ & $\begin{array}{l}-6 \cdot 4 \text { to } 3 \cdot 0 \\
-0 \cdot 01 \text { to } 0.04 \\
-2 \cdot 6 \text { to } 4 \cdot 9 \\
108 \cdot 0 \text { to } 153 \cdot 4 \\
27 \cdot 9 \text { to } 39 \cdot 8 \\
1.35 \text { to } 6 \cdot 14\end{array}$ \\
\hline
\end{tabular}

Table 2 Results of linear regression: dependent variable $=$ grip strength $(N)$; independent variable $=$ forearm muscle $C S A\left(\mathrm{~cm}^{2}\right)$

\begin{tabular}{|c|c|c|c|c|c|c|c|c|}
\hline & Constant & $S D$ & $p$ & Coefficient & $S D$ & $p$ & $\begin{array}{l}r^{2} \text { adjusted } \\
(\%)\end{array}$ & $\begin{array}{l}\text { Residual } \\
S D\end{array}$ \\
\hline $\begin{array}{l}\text { Normals } \\
\text { RA }\end{array}$ & $\begin{array}{l}-48 \cdot 7 \\
-0.02\end{array}$ & $\begin{array}{l}30 \cdot 2 \\
13 \cdot 85\end{array}$ & $\begin{array}{l}\text { NS } \\
\text { NS }\end{array}$ & $\begin{array}{l}9 \cdot 15 \\
3 \cdot 57\end{array}$ & $\begin{array}{l}0.98 \\
0.50\end{array}$ & $\begin{array}{l}<0.01 \\
<0.01\end{array}$ & $\begin{array}{l}46 \cdot 3 \\
33 \cdot 4\end{array}$ & $\begin{array}{l}73 \cdot 64 \\
47 \cdot 43\end{array}$ \\
\hline
\end{tabular}

$\left(\mathrm{cm}^{2}\right) ; \mathrm{U}=$ area of ulna $\left(\mathrm{cm}^{2}\right)$; (note: double fold of skin measured by skin calipers). Area of radius and ulna was taken from published tables of mean bone diameter, ${ }^{10}$ assuming a circular cross section. ${ }^{11}$
To check the precision of the estimated muscle CSA in seven subjects (one normal, six with RA), a computerised scan was performed at the mid-forearm level. The area of muscle and bone, and the area of each bone were found from areas of interest using a light pen and screen; the anatomical CSA of muscle being obtained by subtraction.

Other data collected from patients with RA included duration of disease, Ritchie Articular Index, ${ }^{12}$ the modified Stanford Health Assessment questionnaire (HAQ) ${ }^{13}$ and two other measures of pain and deformity in the hand, the mini Ritchie Index and a deformity index. The mini Ritchie Index for the hand consisted of summing the responses to pressure of the wrist complex, metacarpophalangeal joints two to five and proximal interphalangeal joints two to five, the maximum score being 9 . The deformity index had a maximum score of 15 and was weighted in favour of the wrist; a score of 1 was recorded for each of the metacarpophalangeal joints that was subluxed, a score of 1 was recorded for each of the proximal interphalangeal joints that showed deformity, and a score of 5 was recorded for deformity at the wrist (usually volar subluxation).

\section{Results}

In the seven subjects in whom computed tomographic scans were performed the estimated muscle CSA correlated closely with the actual muscle CSA (fig 1). There was a tendency to slight overestimation of muscle CSA by this method.

We recruited 100 normal subjects and 100 patients with RA. Table 1 shows that controls and patients were similar for age, sex, height, and weight. The patients with RA had a mean duration of disease of 12 years, a median HAQ score of 1.2 (range 0-3), median Ritchie Articular Index of 8 (range 0-40), a median mini Ritchie Index of 2 (range $0-7$ ), and a median deformity index of 3 (range 0-15). Significant differences were found between normal subjects and those with RA for grip strength, pinch strength, and forearm muscle CSA (table 1).

Table 2 and figure 2 show the results of simple linear regression between grip strength and muscle CSA for normal subjects and patients with RA. Multiple regression analysis was carried out using grip strength as the dependent variable and forearm muscle CSA, mini Ritchie Index, and deformity index as the independent variables which were entered together. Each of the coefficients was significant (table 3 ) and $r^{2}$ adjusted was $37.9 \%$-an improvement on using muscle CSA as the only independent variable.

\section{Discussion}

According to the results of the computed tomography study we were able to obtain a good estimate of actual muscle anatomical CSA from anthropometric data. The method used is not new: in the upper arm good correlation has been obtained between esti- 
Table 3 Results of multiple regression for rheumatoid arthritis: maximum isometric grip strength as dependent variable

\begin{tabular}{lcrll}
\hline Predictor & Coefficient & \multicolumn{1}{l}{$S D$} & t ratio & $p$ \\
\hline Constant & $63-1.6$ & 22.42 & 2.82 & 0.006 \\
Muscle CSA & 2.20 & 0.65 & 3.40 & 0.001 \\
Mini Ritchie index & -5.06 & 2.47 & -2.05 & 0.043 \\
Deformity index & -4.66 & 1.52 & -3.06 & 0.003 \\
\hline
\end{tabular}

$r^{2}$ adj $=37 \cdot 9 \% ;$ residual $\mathrm{SD}=44 \cdot 84$

mated CSA and actual CSA as measured by computed tomography ${ }^{3}$ and ultrasound. ${ }^{14}$ Anatomical CSA provides a good correlation with strength despite the obvious limitations in estimation and a poor relationship to physiological CSA, a matter of little concern when subjects are compared at the same site. However, if the functional properties of individual muscles are predicted from anatomical CSAs, grossly misleading results might be obtained. ${ }^{15}$ It should also be noted that, unlike endurance and velocity of movement, isometric strength is independent of muscle fibre type in untrained subjects. ${ }^{16}$

We found significant muscle wasting in rheumatoid arthritis, but the amount of wasting was small compared with the reduction in expected grip and pinch strength. For this reason we attempted to make some allowance for pain and deformity in the joints of the hand. However, it is difficult to assess whether these contrived variables can sufficiently express the problems occurring in vivo. Certainly, multiple regression analysis suggests that the three independent variables of pain, deformity, and CSA only account for about $38 \%$ of the variation in grip strength in this group Arthrogenous muscle inhibition, ${ }^{6}{ }^{17}$ which was not quantified in this study, may well account for a large part of the residual variation.

As the reduction in muscle bulk was not marked, some doubts must remain about the quality of the muscle in rheumatoid arthritis. Electromyographic evidence suggests polymyositis in $85 \%$ of subjects with RA. ${ }^{5}$ Other studies of the voltage tension curve measured by surface electromyography have shown abnormalities in $65 \%$ of patients with $\mathrm{RA}$, although it was felt that the main cause of the abnormality was arthrogenous inhibition rather than primary neuromuscular disease. ${ }^{18}$ Histological investigation in selected subjects with RA has shown myositis in $24 \%$ of cases, primary neuropathy in $26 \%$ and muscle cachexia (defined as a decrease in muscle fibre calibre with an increase in nuclei, changes seen in diseases such as carcinomatosis) in $38 \% .{ }^{19}$ Further work is needed to define this qualitative defect of muscle in RA.

We thank Dr P F Evans for measurement of the CT scans and Mrs B Dibb and Mrs S A Shires for typing the manuscript.

1 Lee P, Baxter A, Carson-Dick W, Webb J. An assessment of grip strength measurement in Rheumatoid Arthritis. Scand F Rheum 1974; 3: 17-23.

2 Helliwell P S, Howe A, Wright V. Functional assessment of the hand: utility, reproducibility and acceptability of a new system for measuring strength. Ann Rheum Dis 1987 46: 203-8.

3 Heymsfield S B, McManus C, Smith J, Stevens V, Nixon D W. Anthropometric measurement of muscle mass: revised equations for calculating bone-free arm muscle area. Am f Clin Nutrition 1982; 36: 680-90.

4 Bruce S A, Newton D, Woledge R C. Effect of subnutrition on normalised muscle force and relaxation rate in human on normalised muscle force and relaxation rate in human subjects

5 Steinberg V L, Wynn Parry C B. Electromyographic changes in Rheumatoid Arthritis. BMF 1961; 1: 630-2.

6 Leading Article. Joint injury and muscle weakness. Lance 1984; 2: 381-2.

7 Davies C T M, Thomas D O, White M J. Mechanical properties of young and elderly human muscle. Acta Med Scand 1986; (suppl) 711: 219-26.

8 Yung P, Unsworth A, Haslock I. Measurement of stiffness in the metacarpophalangeal joint: the effect of physiotherapy. Clin Phys Physiol Meas 1986; 7: 147-56.

9 Arnett F C, Edworthy S M, Bloch D A, et al. The American Rheumatism Association 1987 revised criteria for the classification of Rheumatoid Arthritis. Arthritis Rheum 1988; 31: 315-24.

10 Virtama P, Helela T. Radiographic measurements of cortical bone. Acta Radiologica 1969; (suppl) 293: 1-217.

11 Horsman A, Leach A E. The estimation of the crosssectional area of the ulna and radius. Am $\mathcal{F}$ Phys Anthrop 1974; 40: 173-85.

12 Ritchie D, Boyle J, McInnes J M, et al. Clinical studies with an articular index for the assessment of joint tenderness in patients with rheumatoid arthritis. $Q \mathcal{F}$ Med $1968 ; 37$ 393-406.

13 Kirwan J R, Reeback J S. Stanford Health Assessment Questionnaire modified to assess disability in British patients with Rheumatoid Arthritis. Br $\mathcal{Y}$ Rheum 1986; 25 206-9.

14 Ikai $M$, Fukunaga $T$. Calculations of muscle strength per unit cross-sectional area of human muscle by means of ultrasonic measurement. Int Zeit Phys Arbeit 1968; 26: 26-32.

15 Fukanaga T, Roy R R, Shellock F G, et al. Physiological cross-sectional area of human leg muscles based on magnetic resonance imaging. f Orthop Res 1992; 10 926-34.

16 Maughan R J, Nimmo M A. The influence of variations in muscle fibre composition on muscle strength and crosssectional area in untrained males. $\mathcal{F}$ Physiol 1984; 351 299-311.

17 Hurley M V, Newham D J. The influence of arthrogenous musle inhibition on quadriceps rehabilitation of patients with early unilateral osteoarthritic knees. $B r f$ Rheum 1993; 32: 127-31.

18 Lenman J A R, Potter J L. Electromyographic measurement of fatigue in rheumatoid arthritis and neuromuscular disease. Ann Rheum Dis 1966; 25: 76-84.

19 Haslock D I, Wright V, Harriman D G F. Neuromuscular disorder in rheumatoid arthritis. $Q \mathcal{F}$ Med 1970; 39: 335-58. 